\title{
DIGITALCOMMONS
}

$11-1-2005$

\section{Obituary: Cliff Lunneborg}

JMASM Editors

Follow this and additional works at: http://digitalcommons.wayne.edu/jmasm

Part of the Applied Statistics Commons, Social and Behavioral Sciences Commons, and the Statistical Theory Commons

\section{Recommended Citation}

Editors, JMASM (2005) "Obituary: Cliff Lunneborg," Journal of Modern Applied Statistical Methods: Vol. 4 : Iss. 2 , Article 2. DOI: $10.22237 /$ jmasm/1130803260

Available at: http://digitalcommons.wayne.edu/jmasm/vol4/iss2/2 
בס"ד

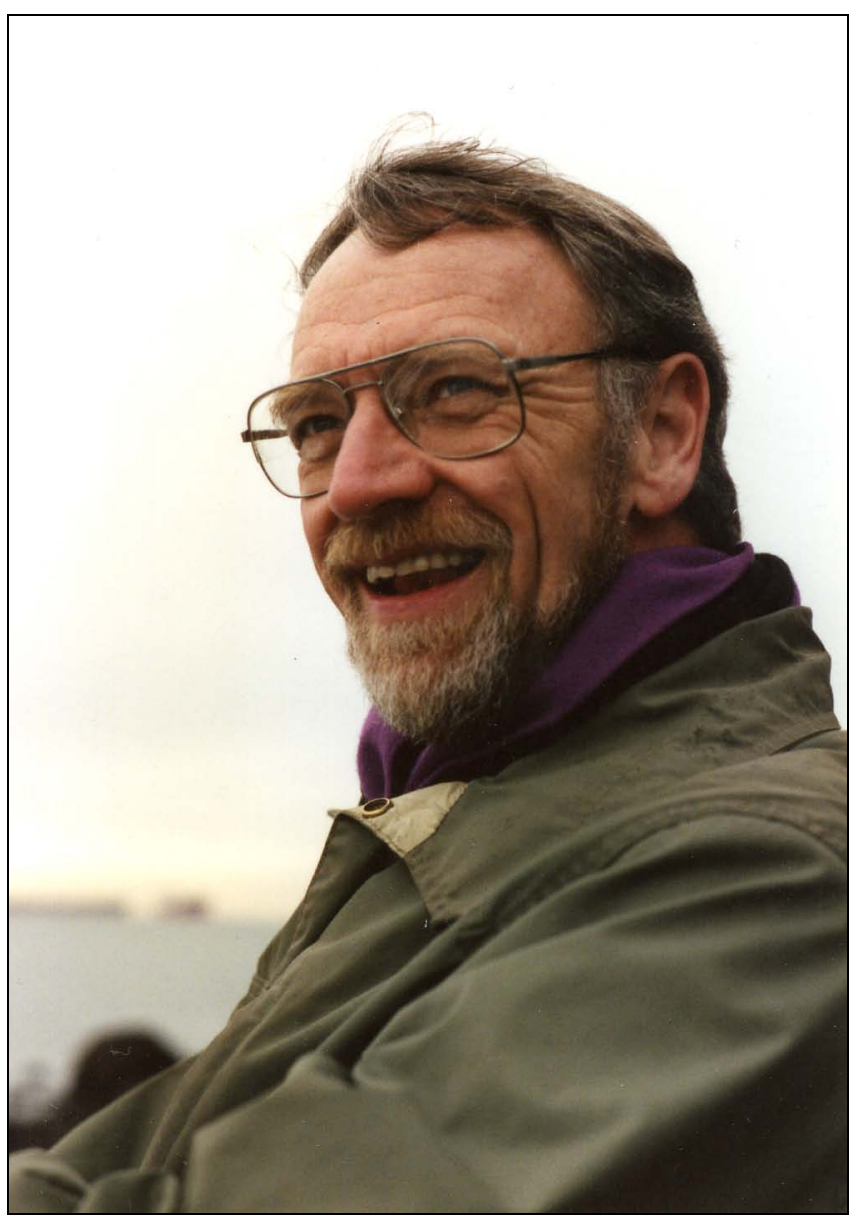

The ideal man would have all the qualities your mother was always going on about when you were a boy - helpful, considerate, courteous; along with those Tom Sawyer thought important - adventuresome, inspired, and inspiring.

Such was Cliff Lunneborg.

$1932-2005$ 